\title{
El color en la arquitectura contemporánea
}

Carlos Tapia, Dpto. Historia, Teoría y Composición Arquitectónicas, Universidad de Sevilla

\section{¿Dónde el color es un argumento para una acción arquitectónica que pudiera explicitar anticipadamente y productivamente su tiempo?}

\author{
“Los atomistas antiguos -Demócrito, Epicuro, \\ Lucrecio...- pensaban que unos entes pequeñísimos, \\ los corpúsculos, penetraban de verdad en nuestro ojo. \\ [...] ¡Es como si un objeto natural penetrase de verdad \\ en nuestro ojo! En el acto mismo de nuestro \\ conocimiento, sea como sea, hay siempre algo \\ fundamentalmente irreversible".
}

René Thom. Parábolas y Catástrofes.

Todo relato se basa en una cierta problemática desatada. Los hechos sitos en ese relato son respuestas a un cierto tipo de preguntas, dejando otras sin enunciar $y$, por tanto, sin contestar.

Las preguntas que yo me formularé a la cuestión del argumento color en la arquitectura actual se ceñirán a un extremo para recorrer el campo por esa banda, sin tratar de colocarnos en todas las posiciones a un tiempo. Si se tratara de generar un estado de la cuestión, se incurriría en la imprecisión de dotar de sentido único a un mundo que se define por su multiplicidad de diagnósticos, y no digamos de formas de aparición. La pregunta, pues, podría definirse como, ¿dónde el color es un argumento para una acción arquitectónica que pudiera explicitar anticipadamente y productivamente su tiempo? A tenor del trabajo que hemos realizado sobre las bases constituyentes de la proyectación contemporánea, pocos resultados hemos obtenido por la vía del color como argumento proyectual primordial. Pero, podemos decir ya, que las aperturas que el color proporciona junto a otras variables, asumiendo una posición extrañada y patológica, antes que complaciente con un marco conceptual, psicológico o significante, son de una productividad extraordinaria así como coadyuvante para administrar lo que nos deja ver nuestro presente mientras se mira a sí mismo.

Conviene señalar que no por hablar de nuestra época, que muchos se empeñan en nombrar y tantos otros en zafarse del nombre, es concebible la injerencia en el problema sin recibir la carga de temporalidades en las que el asunto del color se ha entretejido quiasmáticamente. Ser modernos hoy, o postmodernos, que sigue siendo una persecución embutida en un kinetoscopio, con inicios y finales enlazados de una única escena que se repite, suscita excitaciones nerviosas respecto a los términos que emplea para ordenar su interior. Así, hablar de color hoy no puede desprenderse del todo de antiguas controversias, por ejemplo, entre línea y color. En el Renacimiento, la línea, dicha y hecha para la pintura, la escultura y la arquitectura, contorneando forma, representaba abstracción, cálculo y espiritua- 
- Contra lo gestáltico y hacia lo informacional. Mercado de Santa Caterina. Barcelona. EMBT arquitectos. De los procesos estáticos o gestálticos a los morfológicos dinámicos en el sentido de Goethe, bildung, formación, es decir, ver desde lo ya formado y, desde ello, más allá de sí mismo

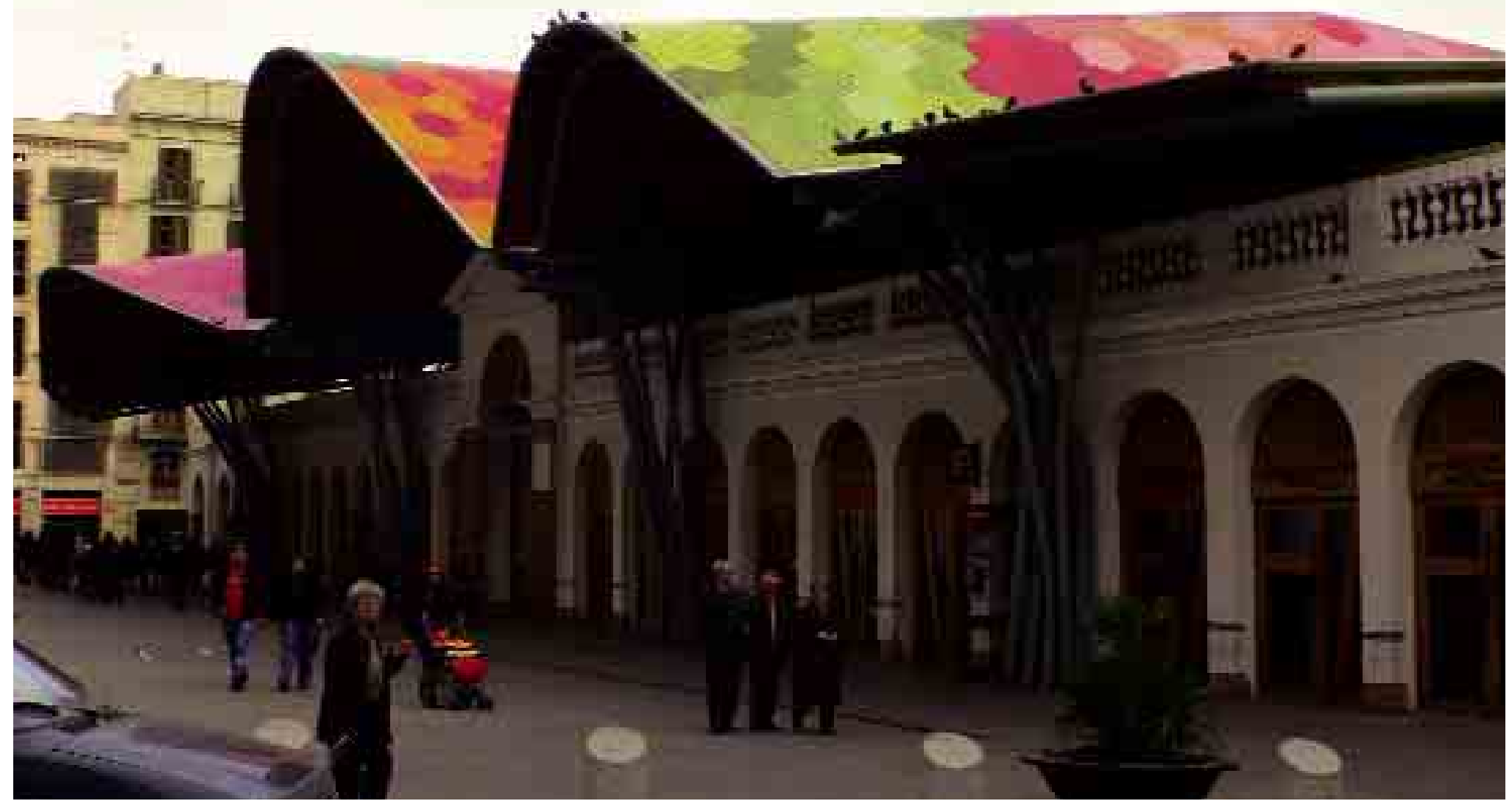



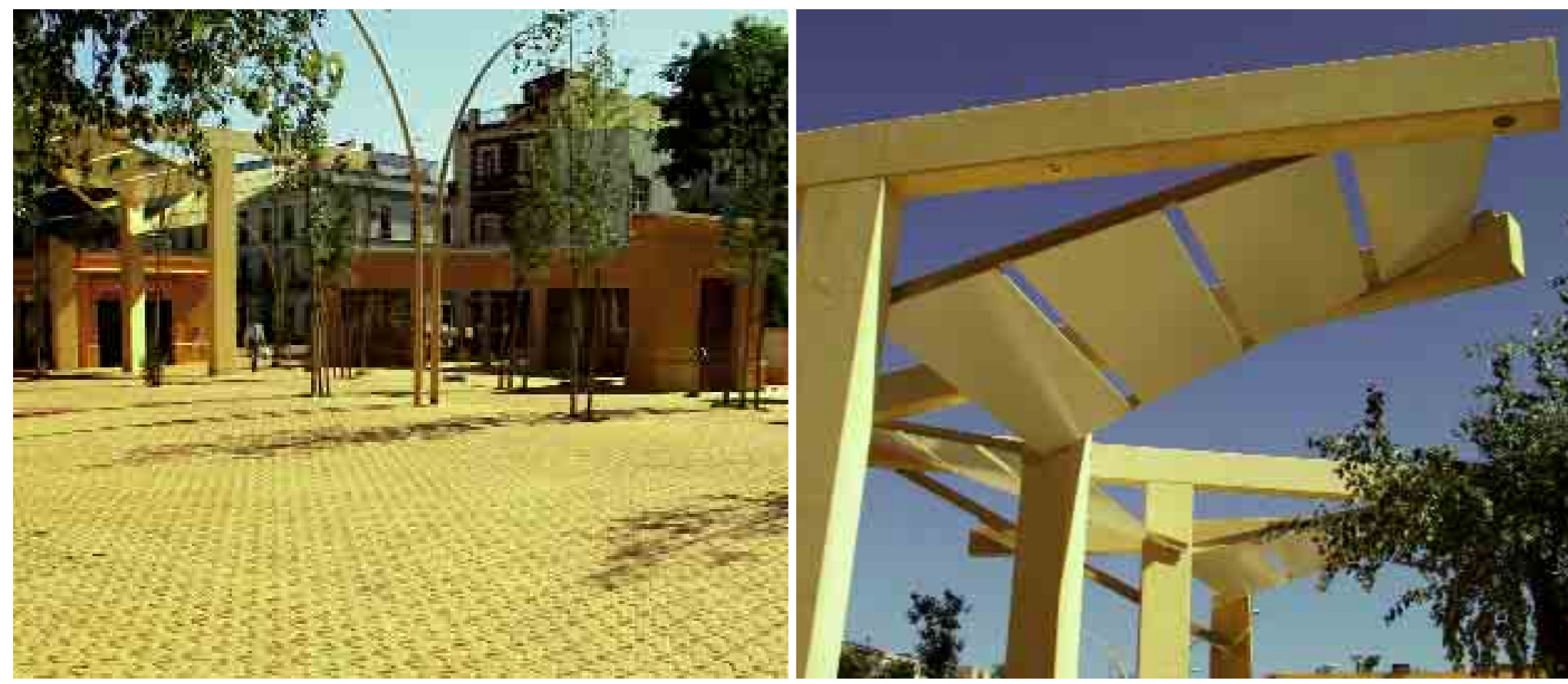

(1) Desde la significación. Alameda de Hércules, Sevilla. Empleo del color como condición patrimonial, donde el albero es el aglutinante del vínculo social. Al proceso participativo desarrollado para este proyecto que demanda la continuidad de los atributos propios de ese materia histórico, se le devuelve en clave significante un único colo que inundará pavimento, luminarias, mobiliario urbano, revestirá edificios existentes, como una pátina de sentido. Sumado a ello, los desplegados envolventes de códigos lingüísticos clásicos sin espacialidad ironiza en formas y se suma a las lógicas del post que el tándem Lapeña/Torres maneja con soltura, como grandes conocedores que son de la obra de Charles Moore. Sobrevolando, las pérgolas del mismo color albero, con inserciones de otro color, sin nombre ni atribución, como negativos o sombras de to único. Como diría Peter Handke, cuando uno observa, y no contempla, se apagan los colores del mundo lidad, mientras que el color, aplicado sin delimitación rectora previa, promovía a la pintura sensualidad, y responsabilidad a la materia. Naturalmente, no acontecen las polaridades sin su genealógica. Es importante reseñar en qué consiste el mundo desplegado en formas y colores que como exterioridad signa nuestra inserción en él, nuestro estar en el mundo, como diría Kant, o arrojados a él, como diría Heidegger. En este sentido, debe nombrarse a San Agustín, para poder ver que a través de su obra espiritual, según leemos de Auerbach, la palabra figura esconde toda la tradición antigua, donde forma hereda los sentidos de lo estático y lo dinámico, el contorno y la formación corpórea, aplicado al mundo y a la naturaleza en general y a cada uno de sus objetos. Figura también sirve al entendimiento de lo externo y sensible, "junto con forma y color y otros términos semejantes".

Pero es que la dualidad ciencia/espiritualidad se establece como dicotomía y no como relación siglos más tarde cuando Newton trataba de explicar como ciencia empírica el fenómeno del color por ángulos mesurables de refrangibilidad de los rayos de luz acromáticos, mientras que Goethe, en su proyecto igualmente científico, con pretensiones de equiparación al del físico y matemático inglés, quiso entender el color en sus propios términos. Con su Farbenlehre de 1810, el enfrentamiento entre ambos se hizo patente y sólo la recuperación del trabajo del autor de Fausto, su teoría del color, en la actualidad y en diversos marcos y para diversos fines, ha logrado poner en justo valor la dimensión y alcances que, en otras circunstancias, habrían determinado otro discurrir de los tiempos. Esa Farbenlehre, dicho por el historiador del arte y la arquitectura G.C. Argan en su libro sobre Goethe La teoria dei colori, es un primer esbozo de una psicología de la percepción. Se trataría de una ciencia del color desde lo sensorial, donde el fenómeno es dependiente del observador que se entrelaza en la individualidad del mismo. El atrevimiento de Goethe consistió, y fracasó por ello, en transducir un argumento de un microcos- 
$\rightarrow$ Visibilidad sobre y trans-epidérmicas. Biblioteca Uithof. Utrecht W. Arets. Del arte como mimesis pasamos al arte como creación y, finalmente, mimesis de mimesis Juego de tatuajes tautológico y ensimismado que embelesa, en los transvases de los modos de hacer del arte hacia la arquitectura

$\rightarrow$ Arte contra el fenómeno. Museo Guggenheim. Billba FCehry Para salir del error de la confusión del arte con e fenómeno físico, Benedetto Croce retira de la noción de arte aquella parte que confunde el tocar la pompa de jabón, cuando tratamos de tocar los colores del arco iris inserto en ella. No se trata de admirar el reflejo bauhausiano como materia, sea hormigón o titanio, sino aquello que el arte provee, la imposibilidad de su constructividad, convencionalidad estética y utilidad

$\Theta$ Textualidad como superposiciones -cromáticasinfinitas. Centro Aronoff Cincinatti. P. Eisenman. Más fuera que dentro del espectro visible, la materia cinética del Aronoff no rezuma sentido, ni sensibilidad, ni significancia. Pura terceridad, mina cada certidumbre atiende a lo inestable de la perdurabilidad, recorriendo complexamente el tiompo aqui contralas nociones del color: leyendo más lento que la memoria, más rápido que lo tectónico
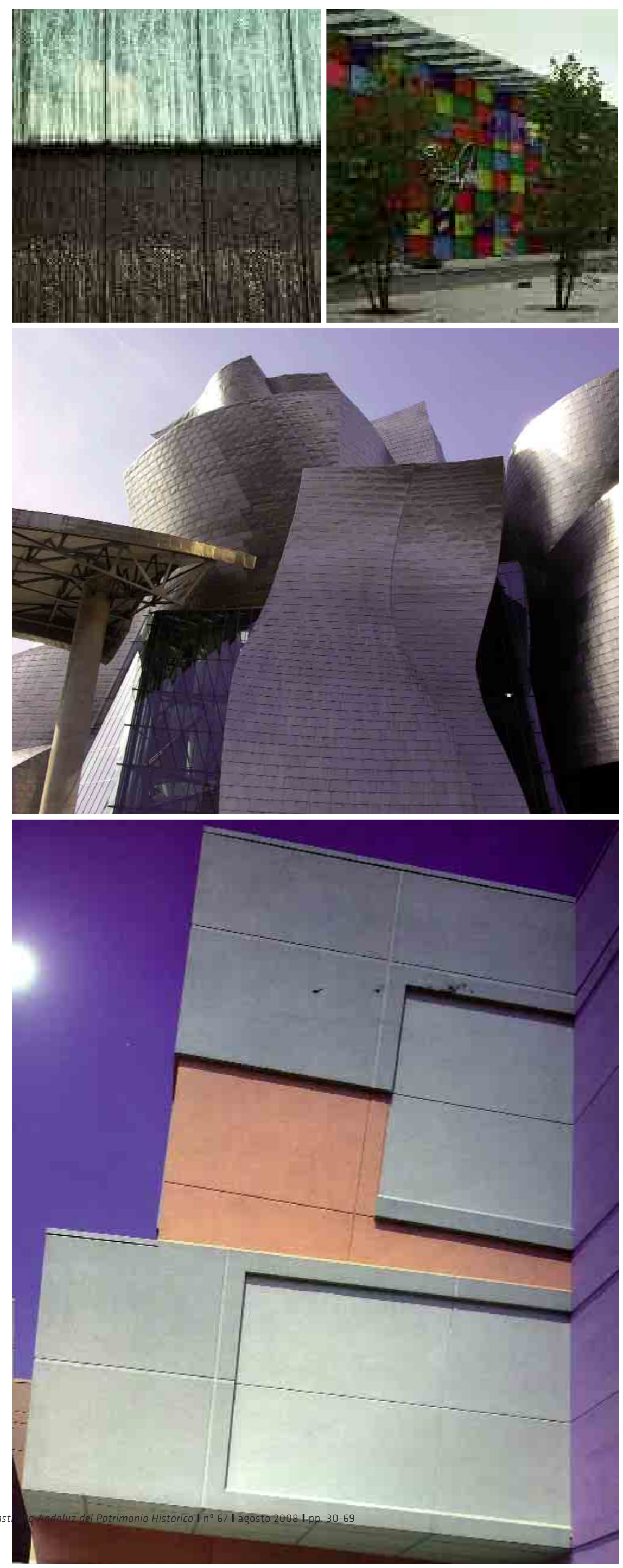
- Gestáltico-tecnológico. Comercio en Almere, Holanda. Alsop\&Störmer. Recorridos por la gama básica del espectro de lo evidentemente visible impelidos por la gracia novedosa del desarrollo tecnológico. Percepción al modo de un calibrado de impresión de una imagen mos, como la percepción individual, a un macrocosmos como descripción del fenómeno. El color, contra la noción de Aristóteles, que lo consideraba un carácter superficial o accidental, alcanza durante el siglo XX una dimensión profunda, o de noesis, que significa visión intelectual, pensamiento 0 , desde la fenomenología de Husserl y Merleau-Ponti, Sartre o Dufrenne, acto intencional de comprensión o intuición entre el objeto y el sujeto.

Sin embargo, si algo define nuestro ahora con algo más de intensidad es la disolución definitiva del par sujeto/objeto y la entrada en pérdida de lo fenomenológico. No su completa desaparición, sino la transmutación en deriva o reconstitución por insuflo de alientos desde otros órdenes, como las nuevas ciencias o los procesos de transversalidad con las artes desde y hacia la arquitectura.

En un mundo donde la emoción no está en el hecho en sí, sino en la constante posibilidad de encontrarlo, desdeñando ese hecho por la codicia del consumir; si los valores con los que colegir la arquitectura se han tornado utilitarios, hierático-estéticos, metafísicos o políticos, la presencia de las cosas no puede dirimirse por intuición sensible en oposición, o como orden paralelo, a la intelectual suprasensible. La arquitectura se torna en ese enfrentamiento ensimismada e insatisfactoria. Ni inducción desde el atributo del color -ni del espacio o la forma- ni deducción, por el movimiento del cuerpo en el espacio. El filósofo y matemático Ch. S. Peirce, que renace hoy con fuerza desde el XIX, propone un mejor término -inferenciaspor el que recorrer esos dos modos de tener razonamientos, sumados a un tercero, la abducción, que trata de la formación de hipótesis para explicar hechos sorprendentes, extrañamientos.

En términos peirceanos, se mantiene en lo cualitativo del color una primeridad, pero para nosotros el mundo se entiende mejor desde la terceridad. Es decir, la generalidad de la primeridad tiene la posibilidad de encarnarse totalmente, disolverse indefinidamente en hábitos

\section{Algo cambia o nos sorprende cuando el color no es sólo percepción que se aproxima como onda, sino como corpúsculo, cuya materialidad y manejo equivale a
otras claves proyectuales}

no cuestionados. La terceridad lleva la información a la mente o determina la idea y la corporiza. Y si he dejado para el final la segundidad, o el fenómeno, es para decirlo estrictamente con palabras de Peirce: "la segundidad es un sentimiento de conmoción, percibido como existente, y nada más". Como en la cita de nuestro inicio, algo cambia o nos sorprende cuando el color no es sólo percepción que se aproxima como onda, sino como corpúsculo, cuya materialidad y manejo equivale a otras claves proyectuales como el tiempo, el espacio, el lugar o la forma.

A partir del entramado dibujado hasta aquí, precipitado e intencional, léanse de nuevo las imágenes que acompañan a este texto como situadas en algunas plataformas de acción arquitectónica -como inferencias- que recorren los distintos flujos turbulentos y extrañados de presentes coetáneos, pero distinguibles por el entendimiento del color, sea psicológico, fenomenológico, o significante.

Imágenes: todas las imágenes son del ARCHIVO FOTOCRÁFICO DE CARLOS TAPIA, salvo las del Mercado de Santa Caterina, de José AMO MORENo, y la

correspondiente al Museo Guggenheim de Bilbao, d Víctor Fernández SALINAS, a quienes agradecemos su amable cesión 


\section{Planes del color de centros históricos: el ejemplo de Málaga}

La revitalización de los centros históricos es una prioridad en todos los programas urbanísticos municipales y, tarde o temprano, se acaba planteando la recuperación de su paisaje urbano. Está consensuado basarse en el mantenimiento y conservación de los signos de identidad autóctonos; los planes especiales y ordenanzas de rehabilitación plantean estrategias para la conservación de las edificaciones históricas, pero cuando se llega al color, recurren a frases como: ... "los colores serán los tradicionales de la zona "...." los materiales y colores de las fachadas armonizarán con los del resto del casco "etc. Se trata de expresiones cargadas de buenas intenciones pero que no garantizan la preservación de los ambientes locales, ya que la determinación del color se acaba improvisando durante las obras en función de las cartas comerciales y tanteos subjetivos. Para hacer frente a todo ello aparecieron los Planes del Color de los Centros Históricos.

En Europa, a finales de los años 70, empiezan los estudios sobre color urbano. Los primeros ejemplos (Turín, Bolonia, Marsella, etc.) parten de tesis doctorales centradas en el estudio de documentos de archivo. A nivel español fuimos pioneros en plantear, a finales de los 80 del pasado siglo, el Plan del Color de Barcelona. Conocedores de las experiencias italianas, propusimos al Ayuntamiento de Barcelona una metodología diferente, basándonos en el análisis estratigráfico de las propias fachadas. A ese primer Plan del Color le siguieron otros muchos (Melilla, Sevilla, Gerona, Toledo, etc.) pero en cada caso nuestra metodología partía de la identificación científica de las preexistencias locales y de su encuadre histórico y arquitectónico. Un ejemplo de ello fue el Plan del Color de Málaga.

El Plan del Color de Málaga lo encargó, por concurso público, el Ayuntamiento de la ciudad a Gabinete del Color (www.gabinetedelcolor.com) y fue entregado en mayo de 1997. Supuso el estudio de las 1500 fachadas del centro histórico, que se incorporaron a una base de datos con digitalización fotográfica y mapificación cartográfica en función de la época de construcción, estado de conservación y potencial cromático de cada fachada. El estudio documental lo coordinó la historiadora del arte Rosario Camacho y el levantamiento de planos el arquitecto malagueño Fernando Soler. La deducción de los materiales, técnicas y colores originales se basó en la extracción de catas de las fachadas y su análisis estratigráfico por difracción de rayos X y microscopía electrónica, realizados en el Instituto Jaume Almera de Barcelona, perteneciente al Consejo Superior de Investigaciones Científicas.

Mi objetivo como director y redactor del trabajo no era sólo la Carta de Colores, sino documentar el patrimonio arquitectónico de Málaga y establecer los materiales y acabados de los diferentes modelos compositivos de fachadas: Barroco (1700-1830), Ecléctico (1830-1900), Regionalista (1900-1940) y Moderno (posterior a la Guerra Civil).

En función de la época de construcción se establecían las combinaciones de colores y los elementos arquitectónicos a recuperar. Toda la información se recogía en los estudios cromáticos de cada fachada a rehabilitar. Durante la ejecución del Plan estos estudios se materializaron en las propuestas cromáticas de los alzados de las calles Carretería y Álamos. El relevo lo tomó la Oficina de Rehabilitación del Centro Histórico de Málaga que, desde entonces, sigue velando por la gestión y seguimiento del Plan.

Bajo el tópico del encalado tradicional andalusí aparecieron unos muros pintados al fresco con motivos muy coloristas: paramentos imitando jaspeados, tapices y cenefas geométricas, decoraciones figurativas, etc. Pero una de las aportaciones de este Plan fue el redescubrimiento de las Ordenanzas de la Muy Noble Ciudad de Málaga fechada en 1611 pero redactadas en 1556. En ellas se describían todos los quehaceres artesanales, desde los procesos de salazón a las técnicas de coloración con las que los alarifes mozárabes tenían que pintar los edificios. Fue un hallazgo que obligó a descifrar un léxico olvidado y con el que, gracias a la colaboración de la Escuela de Estudios Árabes de Granada y a la confrontación de los análisis petrográficos actuales, se pudieron deducir los colores y técnicas originales. Los escrupulosos gremios nazarís establecieron estas normas para preservar sus oficios, establecían inspectores y fuertes penalizaciones económicas a los infractores. Respecto a las artes aplicadas se discernía entre los pintores de los exteriores -alazeres-y los de interiores -lo morisco-. Los primeros debían pintar al fresco y con cal "bien templada "y los segundos en seco y con yeso, vigilando que "no echen yeso demasiado negruno "y siempre con "colores bien molidos “. Las técnicas y los pigmentos estaban preestablecidos. Para las fachadas: albayalde (marfil), açofaira (dorado), almagra (cerámico), prieto (sombra). En los interiores: bermellón, azarcón (minio), anaranjado, verde, añil y rosado. Esta paleta siguió en las arquitecturas posteriores y los tonos amarillos, ocres y óxidos siguen siendo los dominantes en la Carta de Colores malagueña. Como en todos los Planes del Color que realizamos, no sólo establecemos los colores y texturas de los paramentos, sino también los de carpintería y cerrajería así como las reglas de armonización entre ellos.

La preocupación por regular el aspecto exterior de las edificaciones no es algo moderno, ya hemos visto cómo en Málaga se regulaba desde el S. XVI. En Barcelona el arquitecto municipal Josep Mas i Vila ya establecía una carta de colores en 1830. En el reciente trabajo que, por encargo de la Xunta de Galicia, hemos desarrollado en el Centro Histórico de Lugo, también hemos localizado unas Ordenanzas de 1879 que determinaban los colores de las fachadas. Lamentablemente estos documentos son sólo papel y testimonio de una época, no habiendo encontrado las cartillas o muestras de los colores que supuestamente tenían que estar depositados en secretaría para consulta del ciudadano modélico. Por todo ello los Planes del Color no pueden basarse exclusivamente en la investigación documental. Defendemos que debe de ser un trabajo pluridisciplinar encargado a profesionales especializados, huyendo de patrocinios comerciales que acaban por banalizar el rico patrimonio cromático que atesoran nuestros centros históricos. 
